\title{
Apply Space Syntax to Design a TOD land Use Plan
}

\author{
C. N. Li and Y. K. Hsieh
}

\begin{abstract}
TOD-related studies have mostly come with empirical models and urban design concepts, lacking theoretical basis and perched on pending assessment about whether regional planning is in line with the TOD ideas and orientation. Therefore, how to alter the current TOD patterns by, instead, taking the walking environment as the main appeal in order to shape up friendly living surroundings has become the top issue in the development of Taiwan's TOD cities. In the discussions, this paper tries to explain how to rearrange the land use around MRT stations in order to get people attracted to walking. The main results of this study include proposed integration of TOD land development with the walking environment and, based on the analytical findings, bringing in TOD ideas and concepts for future land development.
\end{abstract}

Index Terms-Transit-oriented development, space syntax, land use.

\section{INTRODUCTION}

Ever-increasing carbon dioxide emissions have worsened global warming, created climate abnormalities, and prompted energy shortages, which has awakened countries all over the world to the potential crisis. In early 1990, the European developed countries took the initiative with new urbanism to create the planning and design concept, known as Transit Oriented Development (TOD). Today, TOD has become the new urbanism that integrates land use with transportation [1], and many empirical cases have proved its abundant efficacies As a result, under the concept of Growing Cooler of urban land development and the guidance of the Green Tea Act, The U.S. has been working on re-directing its urban development toward sustainability. So far there have been more than 100 cities have been trying to reengineer their city blueprints into TOD patterns, along with more than 4,000 TOD plans on land uses [2]. This means that the TOD concept has become a new trend in urban planning.

Foreign TOD studies show that those countries' development is built on the public's willingness to use alternative transportation methods by choosing walks and public transit systems. In other words, the reason that TOD requires constant emphasis on how to enhance public transit volume and reduce the use of private vehicles is that it is mainly in great need of public support. If citizens use only private vehicles to move quickly within cities, they will be passively moving toward their destinations within the non-continuous fragments of urban geography, and the urban space will lose its attraction. Consequently, long-term neglect of the walking environment and its network can make people

Manuscript received November 13, 2013; revised March 12, 2014.

C. N. Li is with Department of Natural Resource, Chinese Culture University, Taipei, Taiwan, 11114 (e-mail: ljn@ulive.pccu.edu.tw).

Y. K. Hsieh is with Graduate Institute of Architecture and Urban Design, Chinese Culture University, Taipei, Taiwan, 11114 (e-mail: kenszoids@gmail.com). on the move want to quickly pass through the urban space without any desire to staying or take note of the changes in their surroundings. If this is the case, the economy will not be energized, nor TOD ideas fulfilled. Under these circumstances, although private vehicles bring about convenience and reduced physical distance, they also sacrifice people's interactions with one another as well as widening the mental distance between people. In view of this, how to make the walking environment more attractive will become one of the major issues concerning urban development with TOD concepts.

Looking at Taiwan's TOD of recent years, we see that traditional TOD planning only emphasizes radial land use by raising the land-use intensity (density) in areas within 300 meters of MRT stations, whereas gradually decreasing the intensity further away, so that people can be concentrated toward the center of activities, therefore enhancing the volume of public transit. However, this strategy overlooks an important factor, i.e. the manner and course of the public's moves need to be contiguous, and this under-thinking has led to the consequence that people are still using private vehicles to get to MRT stations. What's worse, this imperfect strategy only takes the land-use element into consideration when trying to affect the public's willingness to walk, but retains the planners' wishful thinking without taking into account the real needs of people who take walks. For instance, in areas of high-density land use, if the surrounding walkways are narrow and difficult to walk through, people will not be interested in taking walking routes. All in all, the biggest constraint on the current TOD implementation lies in the lack of space attraction as well as a dearth of walker-friendly environments [3]. Moreover, current domestic TOD studies mostly consist of empirical models and urban design concepts. These are inadequate when it comes to theoretical foundations and remaining at the assessment level of whether area planning is in line with the TOD ideas and orientations. Therefore, insufficient are empirical studies on how to deploy the land use around TOD areas, how to integrate with walking environment, and how to operate to fulfill TOD. These inadequacies have led Taiwan's TOD to reverse planning of land development guiding public transportation, that is, land-use intensity dominates the deployment of public transit systems. Consequently, the choice of locations for public transit systems is biased toward the needs of land development [4], which drives many urban land development issues.

Therefore, we need to think about how to fulfill human-oriented urban design by discussions on the TOD surrounding environments and land-use deployment, so that the flow of crowds can transform the public's urban experience into contiguous recognition and people's sense of identity with the urban space can be built. In this way, people's vehicle transportation habits can be changed and 
interaction with urban space can be positively affected. Thus, Taiwan's existing TOD patterns can be altered to walking environment-based thinking, in search of optimal land-use deployment around MRT stations in order to create a better living environment and to encourage more efficient land use. This is currently the top issue facing of Taiwan's urban TOD.

\section{LITERATURE REVIEW}

\section{A. Application of Space Syntax}

According to Space Syntax, a road network is shaped up by both nature patterns and urban organization, and can be seen as a single contiguous space system. This system can be divided into several elements, such as the analysis of road network selection, and the correlatively affected and connected spaces extracted from road networks and graphs. Hillier (1999) suggested using graphical illustrations as one of the key methods of Space Syntax, i.e. using a graph composed of various vertices on an axial map which constitute edges. On such a graph, streets are shown as vertices which present the relationships among them [5]. Meanwhile, Penn (1998) in his major research, argued that the connectivity of a road network and land use had a positive correlation, i.e. a more frequently used road could attract walkers and make its land-use intensity stronger [6]. In addition, in his comprehensive empirical analyses, Hillier (2007) discovered that Space Syntax could be applied to public spaces of all sizes, and the analytical results from different cities could be compared to one another. Recent studies show that the optimal distance scale may come from the countryside, a single urban area, or local towns [7]. Also, Turner (2007) argued that space-related centrality could be used to better predict human movement behaviors than the point-to-point connection. In other words, the center-line street network was better than traditional axial graphs in predicting moving behaviors [8]. Again, Nenci (2007) pointed out that, to present different systems, space syntax could be compared against transportation models [9].

In recent years, many emerging and well planned areas in foreign countries have adopted Space Syntax as the basis for their urban planning. For instance, the Arabian City of Jeddah has applied this theory to improve its midtown villages which were economically excluded and geographically segregated due to long-time poor connectivity with the outside world. Another example is the British Nottingham old square, where people's moving paths were found to be blocked by obstacles. As a result, $78 \%$ of the citizens who took walks made a detour to avoid the square center; the means of improvement was to redeploy the square space in order to uplift the square's usability so that people could freely walk through the center to any other space. Whereas, the main streets of the British City of London are crowded with traffic, and therefore its citizens are more willing to move by walks. After Space Syntax is added to the analysis of walkers' road network, empirical studies reveal that, although each person may choose his/her own route, the aggregated choices will finally make a stable pattern. Also, Peponis et al. (1997) took on the U.S. City of Atlanta in an empirical study and proved that the empirical space syntax could be used to explain the moves of walkers and vehicles in different urban areas [10].
Meanwhile, Hillier and Sohn (2000) applied this method to locate the distribution of urban crimes, and in their research, they compared space syntax indicators against crime rates, and the results showed that area connectivity was reversely proportional to the crime rate [11].

The above empirical case studies illustrate the fact that Space Syntax is mainly used to analyze road networks patterns, and that the analyzed objects are not lands but the surrounding road and venue spaces. Chen (2008) argued that such a methodology was essentially different from other urban analysis methods that were based on land lots as analytical units. Enström and Netzell (2008) suggested that it was different from the traditional gravity model which only considered the move from one spot to the other [12]. Turner A. (2007) further pointed out that the centrality of connected spaces could better predict human move behaviors than point-to-point connections, i.e. the center-line street network is better than a traditional axial graph in predicting move behaviors. Evidently [13], Space Syntax not only takes into consideration the entire urban street network and the correlation of specific roads against all other roads, but also accommodates people's experience of road selection. In other words, Space Syntax transforms the past physical-distance accessibility studies into the research foundation based on the topological accessibility of road networks.

\section{B. The New Urbanism TOD with Walking Environment and Land Use}

Today's metropolises take TOD concept to expand their urban transit systems in order to deal with the increasing need of tourism for accessibility. Rahul (2013) used the U.S. City of Denver as an example to explore the causes of urbanization, and found that between 1997-2010, Denver used rail transport systems and the TOD characteristics of high-density and high mixed-use development to uplift the city's average urbanization density [14]. However, argued that TOD was different from past urban planning ideas in that TOD sets out with sustainability and growth wisdom, takes high-efficient public transit systems as the urban development spindle, and comes with aesthetics, urban design concept, and diverse and high-intensity land use so as to shape up the development structure with highly concentrated and residence-friendly urban spaces. However, Chen argued that during the construction of MRT, land development patterns around the stations needed to be adjusted for the buildup of the urban landscape so that the urban mechanism can be energized in order to bring in economic benefit [15]. The surrounding walkways need to be restructured for greater accessibility in order to facilitate inhabitance and commercial shopping. Also, Alpkokin (2012) took the City of Istanbul as a study case and found that TOD helped to bring about long-term potential of land development with higher accessibility which uplifted new residential development and increased land value at the same time [16]. The ultimate goal of urban land development was to reach the most appropriate configuration and gain economic value, and under TOD planning models, land resources could be efficiently utilized to avoid land waste and traffic jams. Integrated land utilization could serve to raise the attraction and utilization of transit systems. Therefore, by way of assessment of traffic impacts, the urban planning, land 
a process is sustainable, it can be carried out over and over without negative effects on the environmental effects or high costs. The definition of Sustainability for the purposes of this Master Plan (United Nations World Commission on Environment and Development) is: "Sustainability meets the needs of the present without compromising the ability of future generations to meet their own needs."[10].

\section{B. What is Sustainable Development?}

World Commission on Environment and Development (WCED-1987) established the definition of sustainable development as "a development that meets the needs of the present generation without compromising the ability of future generations to meet their own needs" [10]. Since the term "sustainable development" came into use in the 1970s, it has been used to mean many different things - as have terms such as sustainable cities and sustainable urbanization. Although the original use of the term sustainable development was intended to place a higher priority on directly meeting human needs while considering development's environmental and ecological implications. If we go back to the term's original meaning, when applied to cities, it comes down to whether two goals can go together. Whether cities can be healthy, enjoyable, resilient places to live and ensure that the draw of their populations' consumption and enterprises' production on local, regional and global resources and sinks is not disproportionate [11]. In this context, Moore [12] claims that there is a triangular conflict among economy Fig. 1, ecology and equity as key sustainability contributors in terms of strategy achievement. A balance between development, property and resource discourses is required to achieve an integrated sustainability in an urban context. Such a balance has more opportunity to make the city more profitable, fairer and greener for stakeholders, developers and governors.

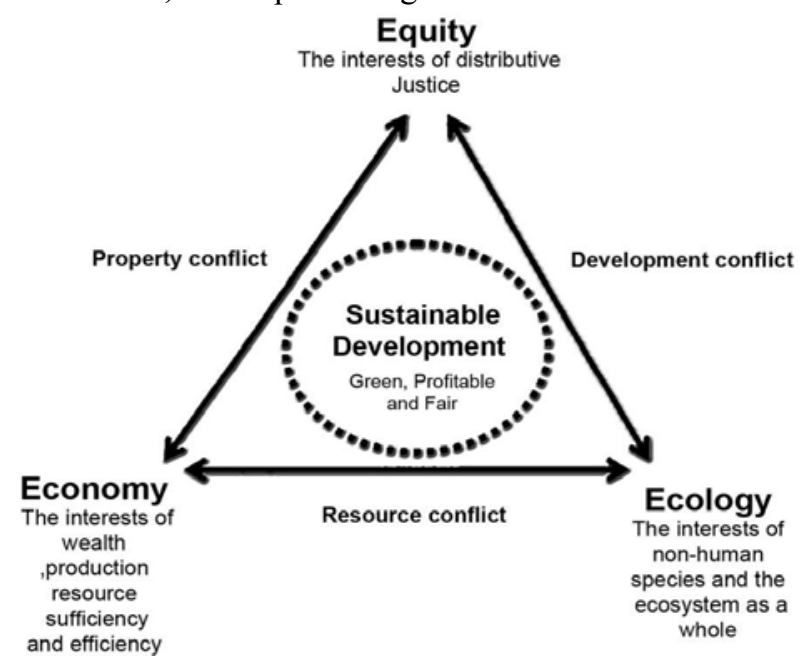

Fig. 1. Triangular conflict to achieve sustainability [12].

\section{What is Sustainable Cities?}

Designing Sustainable Cities in the Developing World introduces a new perspective on cities which is innovative in scale, content and objectives. In terms of scale, the mainstream urban literature and research on cities in the developing world is, of course, vast. Dominated by a number of recurring themes, these provide both a valuable context and potent insights to support our own perspective. Briefly these include: theories of urbanization; the political economy of cities and the form and consumption of space; demographic, social and spatial reconfiguration under conditions of globalization and structural adjustment; the dynamics of urban economies and the livelihoods of the mass of low income dwellers; urban poverty and environmental degradation; the scope of policy and intervention to manage rapid informal urbanization [13], [14]. Sustainability features strongly in the urbanization literature, but is preoccupied with macro scale processes, issues of governance and institutional capacity and the political economy of urban environmental sustainability [15]-[17].

Sustainable principles of urban development are categorized into management, social-economic and ecological subdivisions. Management principles include local International government responsibility with better environmental understanding, flexibility of environmental policies and long-term strategic visions. Socio-economical category includes appropriate technology and design, creating adequate environmental indicators, standard regulations, market connectedness, supporting by social acceptability and public participation. Ecological principles contain prevention-led actions, integrated activities, using minimum resources (renewable and recyclable), and producing minimum waste, respecting the environmental diversity and expanding local environmental research [18].

\section{What is Sustainable Landscape?}

Sustainable architecture is architecture that seeks to minimize the negative environmental impact of buildings by efficiency and moderation in the use of materials, energy, and development space. Sustainable architecture uses a conscious approach to energy and ecological conservation in the design of the built environment. The idea of sustainability, or ecological design, is to ensure that our actions and decisions today do not inhibit the opportunities of future generations.

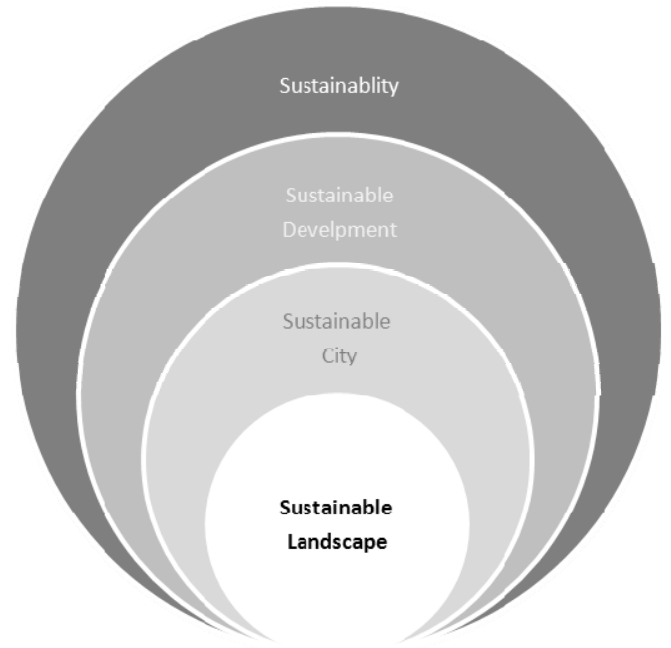

Fig. 2. Hierarchy of sustainability.

Sustainable landscape architecture is a category of sustainable design concerned with the planning and design of outdoor space. This can include ecological, social and economic aspects of sustainability. Sustainable landscape architecture creates ecological designs for the outdoor and urban environment. It begins with appropriate systems which address function, cost, energy efficiency, beauty, and 


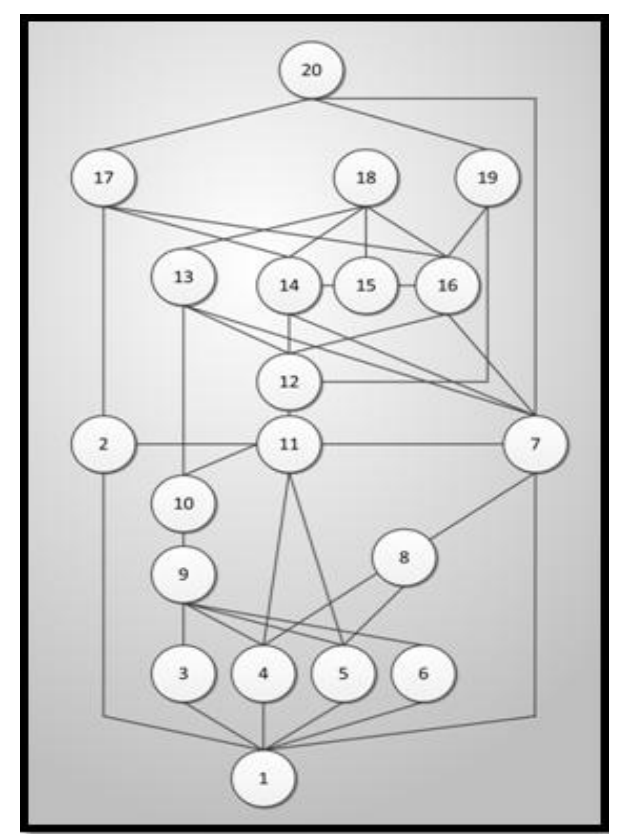

Fig. 4. Connectivity graph.

TABLE II: ANALYSIS RESULTS OF LOCAL MEASUREMENT

\begin{tabular}{|c|c|c|c|c|}
\hline $\begin{array}{l}\text { Analy } \\
\text { sis } \\
\text { unit }\end{array}$ & $\begin{array}{l}\text { Three-step depth } \\
\text { (D) }\end{array}$ & $\begin{array}{l}\text { Mean depth } \\
\left(M D_{i}\right)\end{array}$ & \multicolumn{2}{|c|}{$\begin{array}{l}\text { Standardized integration value } \\
\left(D_{n}\right)\end{array}$} \\
\hline (1) & $(1 \times 6)+(2 \times 8)+(3 \times 5)=37$ & $\frac{37}{20-1}=1.947$ & \multicolumn{2}{|c|}{ 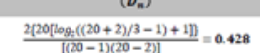 } \\
\hline (2) & $(1 \times 3)+(2 \times 7)+(3 \times 5)=32$ & $\frac{32}{16-1}=2.133$ & \\
\hline (3) & $(1 \times 2)+(2 \times 6)+(3 \times 5)=35$ & $\frac{35}{10-1}=2.333$ & \multicolumn{2}{|c|}{$\frac{2\left(16\left[\log _{2}((16+2) / 3-1)+1\right]\right]}{[(16-1)(16-2)]}=0.506$} \\
\hline (1) & $(1 \times 4)+(2 \times 7)+(3 \times 5)=33$ & $\frac{33}{17-1}=2.063$ & \multicolumn{2}{|c|}{$\frac{\left.2\left(177 \log _{2}((17+2) / 3-1)+1\right]\right)}{[(17-1)(17-2)]}=0.484$} \\
\hline (5) & $(1 \times 4)+(2 \times 7)+(3 \times 5)=33$ & $\frac{33}{17-1}=2.063$ & \multicolumn{2}{|c|}{$\frac{2\left[17\left[\left[\log _{1}((117+2) / 3-1)+1\right]\right)\right.}{[(17-1)(17-2)]}=0.484$} \\
\hline (6) & $(1 \times 2)+(2 \times 6)+(3 \times 7)=35$ & $\frac{35}{16-1}=2.333$ & \multicolumn{2}{|c|}{$\frac{2\left[16\left[\left[\log _{:}((16+2) / 3-1)+1\right]\right]\right.}{[(16-1)(16-2)]}=0.506$} \\
\hline (1) & $(1 \times 7)+(2 \times 11)+(3 \times 1)=32$ & $\frac{32}{20-1}=1.684$ & \multicolumn{2}{|c|}{$\frac{2(20[169:(20+2) / 3-1)+11])}{(180-1)(20-2)]}=0.428$} \\
\hline 8 & $(1 \times 3)+(2 \times 7)+(3 \times 9)=44$ & $\frac{44}{20-1}=2.316$ & \multicolumn{2}{|c|}{$\frac{2(20[1098:(20+2) / 3-1)]+1]]}{[(20-1)(20-2)]}=0.428$} \\
\hline (3) & $(1 \times 5)+(2 \times 4)+(3 \times 4)=25$ & $\frac{25}{14-1}=1.923$ & \multicolumn{2}{|c|}{$\frac{\left.2\left(14+\left[\log _{0}((1)+21+2) / 3-1\right)+1\right]\right)}{[(14-1)(14-2)]}=0.559$} \\
\hline (19) & $(1 \times 3)+(2 \times 8)+(3 \times 8)=43$ & $\frac{43}{20-1}=2.263$ & \multicolumn{2}{|c|}{$\frac{2(20[\log 8((20+2)+3-1)+1])}{[(20-1)(20-2)]}=0.428$} \\
\hline (11) & $(1 \times 6)+(2 \times 9)+(3 \times 4)=36$ & $\frac{36}{20-1}=1.995$ & \multicolumn{2}{|c|}{$\frac{2(200[108:(20+2) / 2-1)+1])}{[(20-1)(20-2)]}=0.428$} \\
\hline (1) & $(1 \times 5)+(2 \times 9)+(3 \times 3)=32$ & $\frac{32}{18-1}=1.882$ & $\frac{2(100) 008:(1)}{[(14)}$ & $\frac{+2) / 3-1)+1]]}{(120-2)]}=0.404$ \\
\hline (1) & $(1 \times 4)+(2 \times 9)+(3 \times 6)=40$ & $\frac{40}{20-1}=2.105$ & 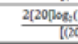 & $\frac{+2) / 3-1)+11}{(20-2)]}=0.428$ \\
\hline 8 & $(1 \times 5)$ & $\frac{38}{10-1}=2.111$ & $\frac{2\left(19 \log _{0: 6}\right)}{[16}$ & $\frac{+2) / 3-1)+11)}{(19-2)]}=0.445$ \\
\hline 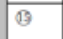 & $(1 \times 3$ & $\frac{31}{15-1}=2.214$ & $\frac{2\left(15 \operatorname{liog}_{0}\right)}{[(15)}$ & $\frac{+2) / 3-1)+11]}{(15-2)]}=0.531$ \\
\hline (17) & (1x & $\frac{36}{19-1}=2.000$ & $\frac{2\left(19 \log _{8}\right)}{[(194)}$ & $\frac{(2) / 3-1)+11]}{(19-2)]}=0.445$ \\
\hline (1) & $(1 \times$ & $\frac{39}{19-1}=2.667$ & $\frac{2\left(19 \log _{0} 8\right.}{1 / 49}$ & $\frac{+2)(3-1)+11]}{(19-2) !}=0.445$ \\
\hline (1) & $(1 \times 6)+(2 \times 5)+(3 \times 6)=32$ & $\frac{32}{16-1}=2.133$ & $\frac{2\left(16\left[\log _{10}\right)\right.}{[160}$ & $\frac{+2) / 3-1)+11]}{(16-2)]}=0.506$ \\
\hline (19) & $(1 \times 3)+(2 \times 8)+(3 \times 6)=37$ & $\frac{37}{18-1}=2.176$ & $\frac{2\left(18 \log _{0}\right)}{\operatorname{lit}(12)}$ & $\frac{+2) / 3-1)+11]}{(18-2)]}=0.46 t$ \\
\hline (2) & $(1 \times 3)+(2 \times 8)+(3 \times 7)=40$ & $\frac{40}{19-1}=2.222$ & 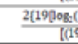 & $\frac{+2) / 3-1)+1]]}{(19-2)]}=0.445$ \\
\hline Analy & & Local conver & ce value & \\
\hline $\begin{array}{l}\text { sis } \\
\text { unit }\end{array}$ & $R A_{i}$ & & & $R_{3}$ \\
\hline (1) & $2(1.947-1)+(20-2)=0.105$ & $0.105+$ & $8=0.245$ & $1+0.245=4.0816$ \\
\hline (2) & $2(2.133-1) \div(16-2)=0.161$ & $0.161+c$ & $6=0.318$ & $1+0.318=3.1447$ \\
\hline (3) & $2(2.333-1) \div(16-2)=0.190$ & $0.190 \div$ & $6=0.375$ & $1+0.375=2.6667$ \\
\hline (1) & $2(2063-1) \div(17-2)=0.141$ & $0.141 \div$ & $4=0.291$ & $1 \div 0.291=3.4364$ \\
\hline (5) & $2(2063-1) \div(17-2)=0.141$ & $0.141+$ & $4=0.291$ & $1+0.291=3.4364$ \\
\hline (6) & $2(2.333-1)+(16-2)=0.190$ & $0.190+$ & $16=0.375$ & $1+0.375=2.6667$ \\
\hline (7) & $2(1604-1)+(20-2)=0.067$ & $0.067 \div$ & $8=0.157$ & $1+0.157=6.3694$ \\
\hline (8) & $2(2.316-1)+(20-2)=0.146$ & $0.146+$ & $8=0.341$ & $1+0.341=2.9326$ \\
\hline (9) & $2(1923-1) \div(14-2)=0.153$ & $0.153 \div 0$ & $9=0.274$ & $1 \div 0.274=3.6496$ \\
\hline (19) & $2(2263-1) \div(20-2)=0.140$ & $0.140 \div 0$ & $8=0.327$ & $1+0.327=3.0581$ \\
\hline (II) & $2(1895-1)+(20-2)=0.099$ & $0.099+0$ & $4=0.231$ & $1 \div 0.231=4.3290$ \\
\hline (13) & $2(1882-1) \div(18-2)=0.110$ & $0.110 \div 0$ & $4=0.237$ & $1 \div 0.237=4.2194$ \\
\hline (19) & $2(2.105-1) \div(20-2)=0.122$ & $0.122+0$ & $8=0.285$ & $1+0.285=3.5087$ \\
\hline (19) & $2(2.111-1) \div(19-2)=0.130$ & $0.130 \div 0$ & $5=0.292$ & $1 \div 0.292=3.4247$ \\
\hline (19) & $2(2214-1) \div(15-2)=0.186$ & $0.186 \div 0$ & $1=0.350$ & $1 \div 0.350=2.8571$ \\
\hline (16) & $2(2.000-1) \div(19-2)=0.117$ & $0.117+0$ & $5=0.263$ & $1+0.263=3.8023$ \\
\hline (1) & $2(2667-1)+(19-2)=0.196$ & $0.196+0$ & $5=0.440$ & $1+0.440=2.2727$ \\
\hline (18) & $2(2.133-1) \div(16-2)=0.161$ & $0.161+0$ & $6=0.318$ & $1+0.318=\mathbf{3 . 1 4 4 7}$ \\
\hline (19) & $2(2.176-1)+(18-2)=0.147$ & $0.147+0$ & $4=0.317$ & $1+0.317=3.1546$ \\
\hline (6) & $2(2.222-1) \div(19-2)=0.143$ & $0.143 \div 0$ & $5=0.321$ & $1+0.321=3.1152$ \\
\hline
\end{tabular}

This research takes the structural characteristics of the walking road network as the data for space accessibility analysis. The walking road network within 500 meters of Banqiao station can be approximately divided into 20 analysis units - the Global convenience value is 1.11; Local convenience values: maximum 6.3694, minimum 2.2727, averaged 3.4635; Connectivity values: maximum 7, minimum 2, averaged 4.15; Control values: maximum 0.483 , minimum 0.188 , averaged 0.3186 . The statistics are shown in Table III below.

TABLE III: ANALYSIS RESULTS OF LOCAL MEASUREMENT

\begin{tabular}{|l|c|c|c|c|}
\hline $\begin{array}{l}\text { Walking road network } \\
\text { space characteristics }\end{array}$ & Analysis unit & Maximum value & Minimum value & Average \\
\hline Connectivity & 20 & 7 & 2 & 4.15 \\
\hline Control Value & 20 & 0.483 & 0.188 & 0.3186 \\
\hline Local (convenience) & 20 & 6.3694 & 2.2727 & 3.4635 \\
\hline
\end{tabular}

\section{CONCLUSIONS}

The convenience of a walking environment is not absolutely decided by the distance from the station. According to the empirical results of this research, Units 16 and 20 are further from the MRT station, but have convenience values of 3.8023 and 3.1152, higher than that of Units 3, 6 and 8 which are closer to the MRT station (within 300 meters) with convenience values of 2.667 and 2.9326 . Therefore, the convenience of the walking environment is not absolutely decided by the distance from the station. If we only look to TOD's traditional means, i.e. raising the land-use intensity for areas within 300 meters from the station and then decreasing the intensity for areas further away, such a land configuration will not effectively take into account road network features and people's walking needs, and therefore TOD development will not be sustainable.

Land-use planning and walking road network features should be integrated. The course of Taiwan's TOD has been demand-oriented. As a result, the commercial activity and population density around MRT stations can be stronger and higher, and the surrounding traffic vehicle road network can be massive and chaotic, which is likely to make the walking environment more inconvenient as it is closer to the MRT station. With traditional planning measures, what could be overlooked is the correlation between the flow and aggregation of crowds and the distribution of land use; also, it is impossible to analyze the connectivity of the environment's status quo with the people in it. Consequently, appropriate space deployment in more subtle relationships won't be possible, because the land-use status quo can easily have significant gaps in the public's cognition. In the past, the urban analysis models were mostly based on the accessibility of physical distance, such as taking a station as the center, with areas 400-800 meters from the station as the impact range. Based on this concept, however, the straight-line distance from the front and rear gates of a public transit station should be same, thus their land use and economic development scales should be identical. The truth is that Taiwan's urban development has been cut off by railways and public transit stations. Developments around the areas of the front and rear gates of a station can exhibit colossal differences, due mainly to the effects of road density, i.e. usually the front gate has roads expended in all directions, while the rear gate may only have underpass links, and thus the two areas evolve into quite different development patterns. This is a deviation from the status quo of Taiwan's 
urban development.

\section{REFERENCES}

[1] J. L. Renne, "Facilitating the financing and development of "smart growth," Transportation Quarterly, vol. 56, no. 2, pp. 23-32, 2002.

[2] R. Ewing, "Induced transportation operating costs," Calculating the Transportation Cost Impacts of New Development: Literature Review Related to Procedures National Cooperative Highway Research Program Project, pp. 83-104, 2007.

[3] H. Dittmar and G. Ohland, The new transit town: Best practices in transit-oriented development, Washington, DC: Island Press, 2004.

[4] C. N. Li and T. Y. Lai, "Applying MOP and MCDM to Design Transit and Land Use Model," Urban Traffic, vol. 22, no. 1, pp. 35-49, 2007.

[5] B. Hillier, "The hidden geometry of the deformed grids: or, why space syntax works, when it looks as though it's shouldn't," Environment and Planning B:planning and Design, vol. 26, pp. 169-191, 1999.

[6] A. Penn, B. Hillier, D. Banister, and J. Xu, "Configurational modelling of urban movement network," Environment and Planning B:planning and Design, vol. 25, no. 1, pp. 59-84, 1998

[7] B. Hillier, A. Turner, T. Yang, and H. Park, "Metric and topo-geometric properties of urban street networks: some convergences, divergences and new results," in Proc. the 6th Symposium of Space Syntax, pp. 12-15, 2007, Istanbul,Turkey.

[8] A. Turner, "From axial to road-centre lines: a new representation for space syntax anda new model of route choice for transport network analysis," Environment and PlanningB: Planning and Design, vol. 34, pp. $539-555,2007$

[9] A. M. Nenci and R. Troffa, "Integrating space syntax in way finding analysis," Space Syntax and Spatial Cognition, Bremen: Univesitat Bremen, pp. 181-184, 2007.

[10] J. Peponis, C. Ross, and M. Rashid, "The structure of urban space, movement and co-presence: the case of Atlanta," Geoforum, vol. 28 , no. 3, pp. 341-358, 1997

[11] B. Hillier and C. F. Shu, "Crime and urban layout: the need for evidence," Secure Foundations: Key Issues in Crime Prevention Crime Reduction and Community Safety, London, pp. 224-248, 2000.

[12] R. Enström and O. Netzell, "Can space syntax help us in understanding the intraurban office rent pattern? Accessibility and Rents in Downtown Stockholm," Real Estate Finan Econ, vol. 36, pp. 289-305, 2008.
[13] A. Turner, "From axial to road-centre lines: a new representation for space syntax anda new model of route choice for transport network analysis," Environment and PlanningB: Planning and Design, vol. 34, pp. 539-555, 2007.

[14] T. M. Rahul and A. Verma, "Economic impact of non-motorized transportation in Indian cities," Research in Transportation Economics, vol. 38 , no. 1, pp. 22-34, 2013.

[15] H. C. Chen, "Manifestation of sustainable development and growth management - look at the airport MRT line from MTR Tung Chung Line TOD development strategy," Land Issues Research Quartely, vol. 11, no. 3, pp. 38-59, 2012

[16] P. Alpkokin and M. Ergun, "Istanbul metrobüs: first intercontinental bus rapid transit," Journal of Transport Geography, vol. 24, pp. 58-66, 2012.

[17] W. M. Wey and Y. H. Chiu, "Assessing the walkability of pedestrian environment under the transit-oriented development," Habitat International, vol. 38, pp. 106-118, 2012

[18] M. J. Jun, J. I. Kim et al., "The effects of high-density suburban development on commuter mode choices in Seoul, Korea," Cities, vol. 31, pp. 230-238, 2012.

[19] A. A. Marwan and R. Raeside, "Modeling pedestrian walking Speeds on sidewalks," Urban planning and Development, vol. 133, no. 3, 211-219, 2007.

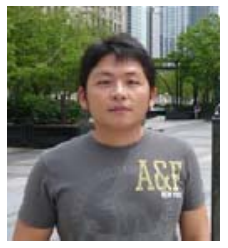

C. $\mathbf{N} . \mathbf{L i}$ is an assistant professor in Department of Natural Resources, Chinese Culture University, Taipei, Taiwan, 11114

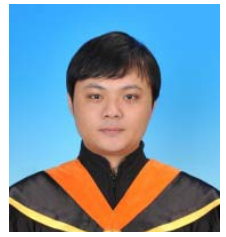

Y. K. Hsieh is Ph.D student in Graduate Institute of Architecture and Urban Design, Chinese Culture University, Taipei, Taiwan, 11114. 